\title{
Individual Approach to Hormone Replacement Therapy - A Computer Assisted Method of Assessment of the Minimal Useful Dose
}

\author{
BM Petrikovsky* \\ Professor and former Chair of Obstetrics and Gynecology, Nassau University Medical Center, USA \\ *Corresponding author: BM Petrikovsky, Professor and former Chair of Obstetrics and Gynecology, Nassau University Medical \\ Center, USA \\ To Cite This Article: BM Petrikovsky. Individual Approach to Hormone Replacement Therapy - A Computer Assisted Method of Assessment of the \\ Minimal Useful Dose. Am J Biomed Sci \& Res. 2019 - 1(1). AJBSR.MS.ID.000507. DOI: 10.34297/AJBSR.2019.01.000507
}

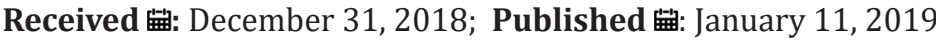

\section{Short Communication}

Estrogen replacement therapy (ERT) was primarily used to treat vasomotor symptoms, it had been increasingly viewed as a way to prevent chronic diseases of aging, including coronary heart disease (CHD), cognitive impairment and osteoporosis [1-3]. Osteoporosis leads to bone fractures. Death rate due to osteoporosis is higher than the mortality rate attributed to breast and endometrial cancer combined. Estrogens are considered the gold standard in assessing the efficacy of various medications in osteoporosis treatment [1,2]. At least $40 \%$ of postmenopausal women in the United States were using ERT before the publication of the Women's Health Initiative (WHI) report, which addressed the risks and benefits of ERT $[1,4]$. WHI trials addressed the most commonly used hormone formulations at the time in the United States -- conjugated equine estrogen (CEE) plus medroxyprogesterone acetate (MPA). Findings from these trials have been extensively published during the past decades [5-7].

Manson et al. [1] conducted an extensive study involving 27,347 postmenopausal women aged 50 to 79 years from 1993 to 1998 at 40 US medical centers; 16,608 women with uterus present were randomized to oral CEE $(0.625 \mathrm{mg} / \mathrm{d})$ plus MPA ( $2.5 \mathrm{mg} / \mathrm{d}$ ) (Prempro) or placebo, and 10,739 women with prior hysterectomy were randomized to oral CEE $(0.625 \mathrm{mg} / \mathrm{d})$ alone (Premarin) or placebo. CHD and invasive breast cancer served as primary outcomes. The study results were summarized as follows: For every 10,000 women taking CEE plus MPA per year, there were 6 more coronary events, 9 more strokes, 9 more pulmonary emboli, 9 more cases of breast cancer compared to the placebo group, and 6 fewer cases of colorectal cancer, 1 fewer case of endometrial cancer, 6 fewer hip fractures, and 1 fewer death compared to the placebo group [1].
In menopausal women aged 50-54 years with moderate or severe hot flashes, night sweats, administration of both the CEE and MPA and CEE alone caused substantial reductions in symptoms (64\% and 28\%, respectively, vs placebo at 1 year). ERT was also associated with statistically significant benefits for physical functioning and general health [1]. Almost half of women aged 60 to 65 years without HRT reported menopausal complaints and nearly two thirds experienced sexual dysfunction $[8,9]$.

Most of the researchers emphasized the importance of developing individual minimal effective dose for each patient with the goal to treat her symptoms and decrease the risk of complications. Shufell et al. [10] studied the risk of breast cancer in HRT users and concluded that the lower breast cancer risk extends to lower doses of ERT prepation [10].

In 2008 [11] we developed a computer algorithm (copyright RS 1800) to provide individual minimal effective dose for a patient calculated based on the following major parameters: Age, weight, uterine status (present, absent), individual hormonal levels (estradiol, testosterone) symptoms - minimal, moderate, severe. Bone health: Normal bone, minimal bone loss, osteopenia, osteoporosis. Those parameters were chosen because based on data in the literature and our experience they appear to be most important for patients' wellbeing $[1,3,5,11]$. Patient symptoms are also taken into consideration in order of priorities. When enrolling into the program, patients are asked to list and rank their symptoms and concerns, e.g., some reported severe hot flashes but were more worried about bone health. The computer program was designed to develop the minimal effective dose of HRT to address the needs of individual patients (e.g., bone loss, hot flashes, vaginal dryness, etc.) Progestins were added if indicated. The computer algorithm is 
applicable to all forms of ERT, including pills, jells, sprays, injections, creams, patches, among others. The majority of our patients were using skin patches because oral estrogens first metabolize in the liver, resulting in higher conversions of E2 to estrone. Transdermal estrogens avoid liver metabolic pathways [10]. Vaginal creams and gels also appear to be a safer form of estrogen compared to pills according to the study conducted by Shilpa et al. [11] These authors examined the association between vaginal estrogen use and multiple health outcomes (myocardial infarction, stroke, and pulmonary embolism/deep vein thrombosis), cancer (breast, endometrial, ovarian, and colorectal cancer), and hip fractures. They included postmenopausal women from the Nurses' Health Study (1982-2012). Authors concluded that vaginal estrogen use was not associated with a higher risk of cardiovascular disease or cancer and was an effective treatment for genitourinary syndrome of menopause (GSM) [11]. GSM occurs in up to $45 \%$ of peri and postmenopausal women adversely impacting physical and sexual health. Vaginal estrogen therapy allows for the restoration of the vaginal epithelium with an increase in the number of superficial cells and normalization of acidic $\mathrm{pH}$, which restores the normal flora and decreases vaginal dryness and dyspareunia [13]. The North American Menopausal Society and the American College of Obstetricians and Gynecologists (ACOG) recommend that low-dose vaginal estrogens be used to treat the symptoms $[12,13]$.

We didn't use vaginal cream as a main form of ERT because of the difficulty to measure an appropriate amount of medication. We used a transdermal patch of estradiol in a multipolymeric adhesive (Minivelle, Noven Pharmaceutical LLC)

These patches come in $0.025,0.0375,0.05,0.075,0.1 \mathrm{mg}$ dosages preparations (Figure 1).

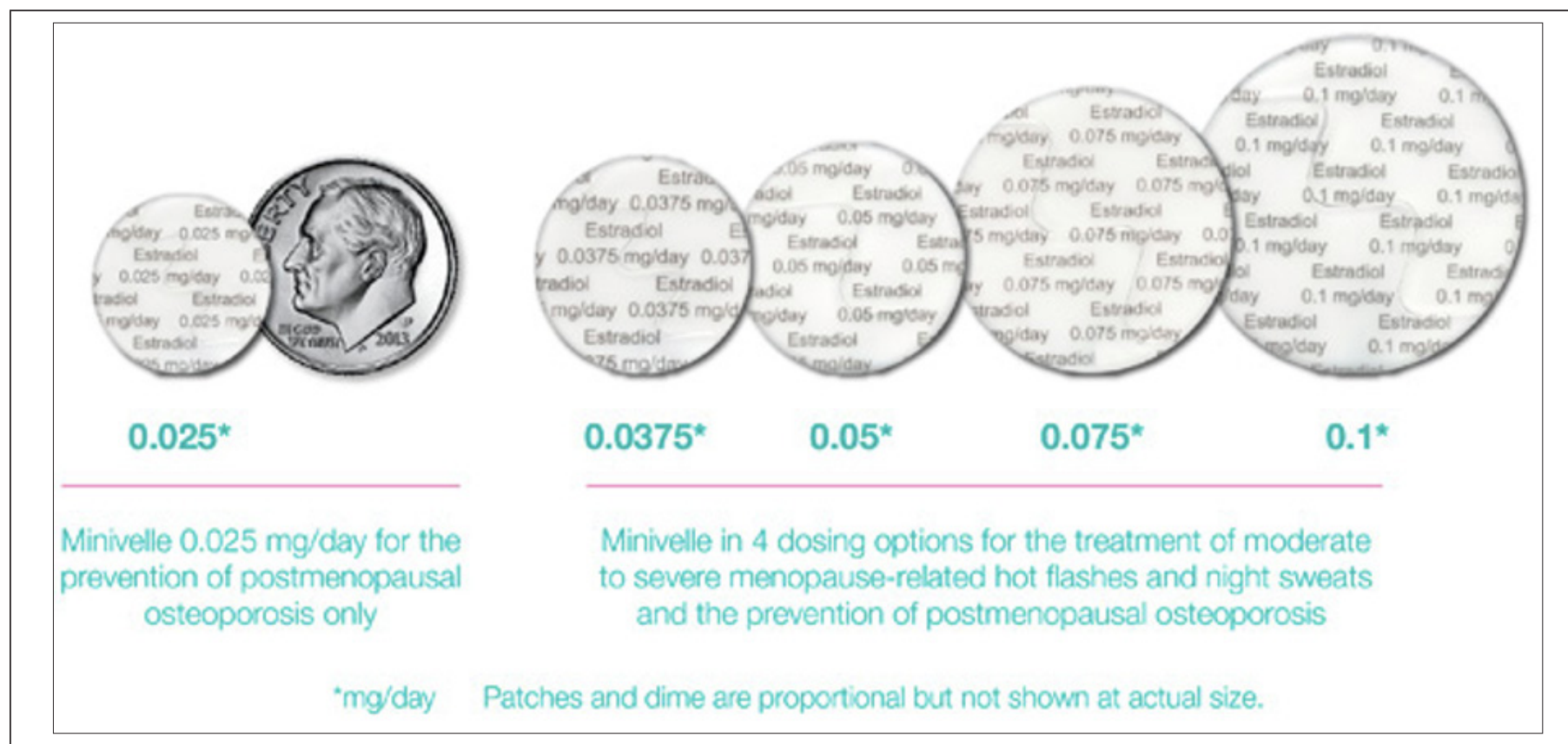

Figure 1.

Below are examples of the practical use of computer-assisted dose selection.

\section{Patient 1:}

a. Age: 62

b. Weight: $78 \mathrm{~kg}$

c. Uterus: Present

d. Menopausal symptoms: Severe

e. Hormonal levels:

1. FSH: $35 \mathrm{mlU} / \mathrm{mL}$

2. Estradiol: $22 \mathrm{pg} / \mathrm{mL}$

3. Testosterone: $18 \mathrm{mg} / \mathrm{dL}$ f. Dose of Minivelle: $95 \%$ of the patch square surface as suggested by the computer algorithm after patient's parameters were loaded into the system.

Patient 2:

1. Age: 48

2. Weight: $92 \mathrm{~kg}$

3. Uterus and ovaries removed

4. Menopausal symptoms: Minimal, desires bone protection

5. Hormonal levels:

a. FSH: $22 \mathrm{mlU} / \mathrm{mL}$

b. Estradiol: $28 \mathrm{pg} / \mathrm{mL}$ 
c. Testosterone: $33 \mathrm{mg} / \mathrm{dL}$

6. Computer recommended dose is $52 \%$ of the patch square surface.

Reassessment is suggested every year since many parameters (age, weight, severity of symptoms) are subject to change.

\section{Patient 3:}

a. Age: 56

b. Weight: $73 \mathrm{~kg}$

c. Uterus: Removed

d. Menopausal symptoms: severe

e. Hormonal levels:

1. FSH: $40 \mathrm{mlU}, \mathrm{mL}$

2. Estradiol: $30 \mathrm{pg} / \mathrm{mL}$

3. Testosterone: $15 \mathrm{mg} / \mathrm{dL}$

f. Dose: $87 \%$ of the patch square surface

The same patient 10 years later:

1. Age: 66

2. Weight: $82 \mathrm{~kg}$

3. Menopausal symptoms: minimal to none

4. Dose: $28 \%$ of the patch square surface

In summary, we report what appears to be the first experience with utilization of a computer program for an individual approach to ERT. The program does not prescribe ERT but rather adjusts the dose to the needs of the individual patient. Because benefits and side effects are usually dose related, the goal of the program is to offer minimally effective dose. The decision of when and if a patient should be started on ERT remains solely hers and her healthcare providers.

\section{Conclusion}

We presented what appears to be the first attempt to use computer algorithm for selecting a minimum useful dose of ERT based on parameters (weight, age, symptoms, etc.) and treatment priorities of an individual patient. We hope that in the near future, patients would be able to input their personal data on a website and receive a minimal individualized effective dose. The website's recommendations will under no circumstances replace the patient's clinicians. The final decision on the type and dose of ERT will be of the patient's healthcare provider.

\section{Acknowledgement}

The author would like to thank Mikhail Tsykin (Australia) for developing the software, and Mario Cohen, MD, (Hartford, CT) \& Gregory Bitterman, Esq. (Great Neck, NY) for their invaluable comments.

\section{References}

1. Manson JE, Chlebowski RT, Stefanick ML, Aragaki AK, Rossouw JE, et al. (2013) Menopausal hormone therapy and health outcomes during the intervention and extended poststopping phases of the women's health initiative randomized trials. JAMA 310(13): 1353-1368.

2. Anderson GL, Limacher M, Assaf AR, Bassford T, Beresford SA, et al. (2004) Effects of conjugation equine estrogen in postmenopausal women with hysterectomy: the Women's Health Initiative Randomized Controlled Trial. JAMA 291(14): 1701-1712.

3. American College of Physicians (1992) Guidelines for counseling postmenopausal women about preventive hormone therapy. Ann Intern Med 117(12): 1038-1044.

4. Hersh AL, Stefanick ML, Stafford RS (2004) National use of postmenopausal hormone therapy: annual trends and response to recent evidence. JAMA 291(1): 47-56.

5. Hays J, Ockene JK, Brunner RL, Kotchen JM, Manson JE, et al. (2003) Women's Health Initiative Investigators. Effects of estrogen plus progestin in health-related quality of life. N Engl J Med 348(19): 1839 1854.

6. Wassertheil-Smoller S, Hendrix SL, Limacher M, Heiss G, Kooperberg $C$, et al. (2003) Effects of estrogen plus progestin on stroke in postmenopausal women: the Women's Health Initiative: a Randomized Trial. JAMA 289(20): 2673-2684.

7. Hendrix SL, Wassertheil-Smoller S, Johnson KC, Howard BV, Kooperberg $C$, et al. (2006) Effects of conjugated equine estrogen on stroke in the Women's Health Initiative. Circulation 113(20): 2425-2434.

8. Gartoulla P, Worsley R, Bell RJ, Davis SR (2015) Moderate to severe vasomotor and sexual symptoms remain problematic for women aged 60 to 65 years. Menopause 22(7): 694-701.

9. Avis NE, Brockwell S, Randolph JF, Shen S, Cain VS, et al. (2009) Longitudinal changes in sexual functioning as women transition through menopause: results from the Study of Women's Health Across the Nation. Menopause 16(3): 442-452.

10. Shufelt C, Bairey Merz CN, Pettinger MB (2018) Estrogen-alone therapy and invasive breast cancer incidence by dose, formulation, and route of delivery: finding from the WHI observational study. Menopause 25(9): 985-991.

11. Bhupathiraju SN, Grodstein F, Stampfer MJ, Willett WC, Crandall CJ, et al. (2018) Vaginal estrogen use and chronic disease risk in the Nurses' Health Study. Menopause 12(17): 12-16.

12. Kaunitz AM (2018) Should we rethink our use of vaginal estrogen? Medscape.

13. Pinkerton JV, Kaunitz AM, Manson JE (2017) Vaginal estrogen in the treatment of genitourinary syndrome of menopause and risk of endometrial cancer. Menopause 24(12): 1329-1332.

14. Petrikovsky BM (2018) Hormone replacement therapy - computer assisted individual approach. W J Gynecol Women's Health 1(4): 1-4. 